\title{
Solid Aneurysmal Bone Cyst of the Distal Metatarsus in a Horse
}

\author{
Nadja Herbach ${ }^{*}$, Christina Terboven², Peter Lambrecht ${ }^{3}$ \\ ${ }^{1}$ Center for Clinical Veterinary Medicine, Institute of Veterinary Pathology, LMU Munich, Munich, Germany \\ ${ }^{2}$ Equine Veterinary Practice, Warngau, Germany \\ ${ }^{3}$ Equine Veterinary Clinic, Zorneding, Germany \\ Email: "n.herbach@Imu.de
}

Received 19 February 2016; accepted 15 April 2016; published 18 April 2016

Copyright (C) 2016 by authors and Scientific Research Publishing Inc.

This work is licensed under the Creative Commons Attribution International License (CC BY).

http://creativecommons.org/licenses/by/4.0/

(c) (†) Open Access

\begin{abstract}
A horse was presented with a slowly growing mass of the distal metatarsal region of the right hind leg. Radiographic examination revealed an eccentric cyst-like lesion with distortion of the lateral margin of the distal metatarsus. The lesion involved approximately half of the metatarsal width, exhibited fine septa, a sclerosed margin towards unaffected bone and a smooth rim of thin compact bone at the periphery. Longitudinal sectioning of the distal metatarsus revealed a solid pale yellow mass with reddish foci and margin. Histologically, the mass consisted of a cell-rich, well vascularized fibrous stroma, containing numerous irregularly shaped trabeculae of woven bone with regular osteocytes. Osteoblasts were observed around the osteoid, and there were foci of numerous osteoclast-like giant cells. The lesion was diagnosed solid variant of an aneurismal bone cyst.
\end{abstract}

\section{Keywords}

Bone Tumor, Aneurysmal Bone Cyst, Horse

\section{Introduction}

According to the WHO, aneurismal bone cysts (ABC) are benign cystic bone lesions, containing blood filled cavities and fibrous septa composed of fibroblasts, reactive woven bone and osteoclast-like giant cells [1]. ABC in man usually arise in the metaphysis of long bones and clinically lead to swelling and pain of the affected area. Radiographically, ABC present as lytic, eccentric, expansile mass with well defined margins and most ABCs are surrounded by a thin shell of subperiosteal reactive bone. Septa within the cysts give the lesion a "soap-bubble-

${ }^{*}$ Corresponding author. 
like” appearance in radiographic images. ABCs are rarely reported in domestic animals, including dogs, cats, horses, and cattle [2], and appear similar to the lesion in humans [1]. The aetiology of the disease is unclear, altered blood flow, trauma and other bone diseases have been suggested to play a role in ABC development of animals [2]. In humans, a genetic component was identified [1]. ABC may arise de novo (primary ABC) or complicate other benign or malignant bone tumours (secondary ABC) in humans and animals, e.g. giant cell tumours, osteoblastoma and fibrous dysplasia [1] [2]. In animals, no age-, sex-, breed- or site-predilection can be assigned due to the sparsity of cases. In humans, ABCs develop in the first two decades of life and have no sex predilection.

The present report describes a solid aneurismal bone cyst of the distal metatarsus in a horse.

\section{Case Presentation}

An eight-year-old Quarter horse gelding was first presented in 2007, exhibiting a small (3 cm in diameter) non-painful mass at the lateral aspect of the right distal metatarsus. Since lameness was not observed, no further diagnostic or treatment efforts were made.

In 2009, the mass had increased in size and caused grade 1 - 2 lameness which was progressive and did not respond to treatment. When the gelding was presented to the Equine Veterinary Practice Gmund, the animal showed grade 2 lameness, and a mass was evident at the lateral aspect of the distal end of the right metatarsus, measuring approximately $5 \times 5 \times 3 \mathrm{~cm}$.

The lesion involved the lateral aspect of the distal metatarsus and occupied approximately half of the metatarsal width. The lateral margin of the metatarsus was distorted, and the lesion exhibited a rim of thin compact bone at the periphery and showed well defined margins. Fine septa could be observed within the lesion, giving it a soap-bubble-like appearance (Figure 1). Due to the size of the process and the risk of a pathological fracture, the horse was euthanized and the right lower hind leg was submitted for post mortem examination. The horse was treated following the national principles of animal care.

Longitudinal sectioning of the metatarsus revealed a solid, firm, pale yellow mass with reddish areas and margins (Figure 2) that could be cut with a knife. Tissue samples were fixed in neutral buffered $4 \%$ formaldehyde and embedded in paraffin. Sections were routinely stained with H \& E, Giemsa, Turnbull and Masson trichrome stain. Histologically, the mass consisted of a cell-rich, well vascularized fibro-osseous stroma with small whorls and interlacing strands of fibrous tissue (Figure 3). The cellular component of this fibrous stroma consisted of well differentiated spindle cells with elongated nuclei, and uniform chromatin. Mitotic figures were rarely observed. Within the fibrous stroma, there were numerous irregularly shaped trabeculae of woven bone with varying degrees of mineralization. The bone spicules exhibited regular osteocytes, and were radiated by collagen fibres. Osteoblasts were observed around the osteoid, and there were foci of numerous osteoclast-like giant cells (Figure 4). In addition, perivascular aggregates of siderophages were observed. The lesion was diagnosed solid aneurismal bone cyst.

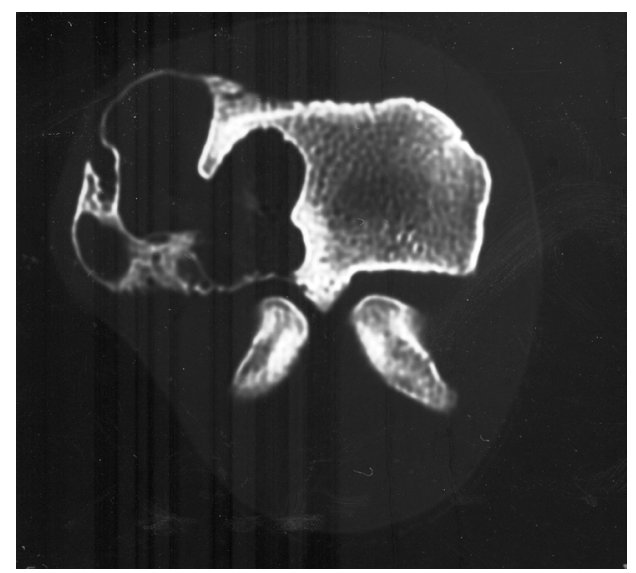

Figure 1. Computed tomography of the metatarsal lesion. 


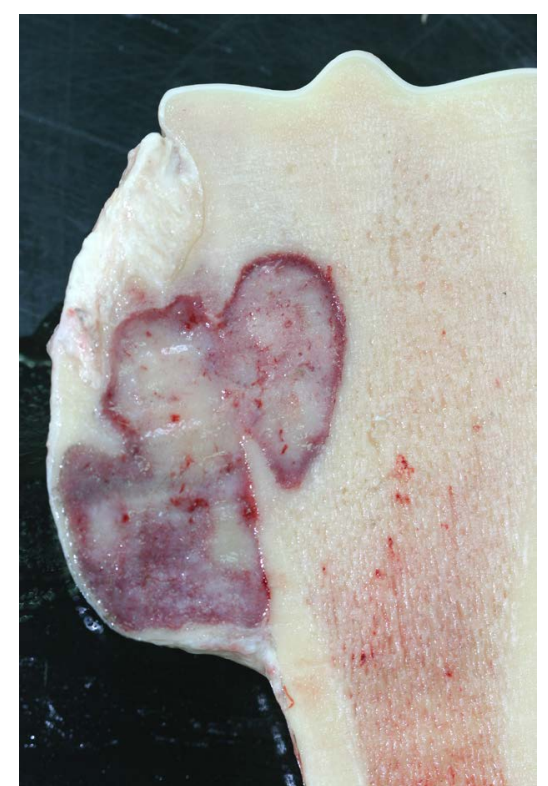

Figure 2. Cross-section of the mass of the distal metatarsus.

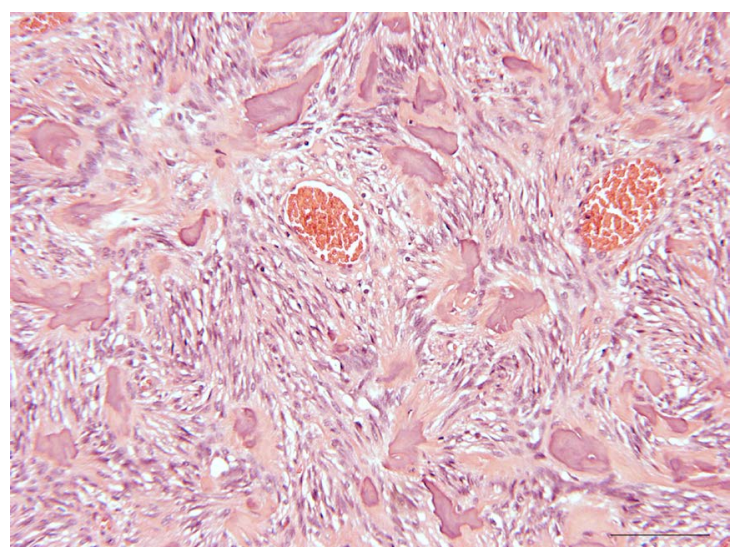

Figure 3. Overview showing the well vascularised fibro-osseous tissue with irregularly arranged mineralized trabeculae in a spindle cell-rich stroma; H \& E stain, bar $100 \mu \mathrm{m}$.

\section{Discussion}

Aneurysmal bone cysts are a well-known benign cystic lesions of bone in humans, most frequently involving long bones, and have occasionally been described in animals [2].

$\mathrm{ABC}$ have rarely been observed in horses, and were described in long bones, including two cases reporting on $\mathrm{ABC}$ of the third metatarsal bone of foals [3] [4], another foal exhibited an ABC in the third metacarpal bone and one in the tibia [5] and a 9 year old horse showed an ABC with pathological fracture in the radius [6]. Four reports are on $\mathrm{ABC}$ of the mandible, including one foal and an adult horse [7] [8]. To our knowledge, this is the first report of a solid aneurismal bone cyst in horses.

According to the radiographic finding, the diagnosis aneurysmatic bone cyst was suspected. Radiographically, $\mathrm{ABC}$ have to be differentiated from osteosarcoma, hemangiosarcoma, fibrosarcoma and plasma cell myeloma [2]. A malignant bone tumour, such as osteosarcoma, may be excluded by radiographic findings, since the lesion described showed a sclerosed rim around a well circumscribed process, as well as a thin rim of bone in the periphery and a smooth surface [9]. 


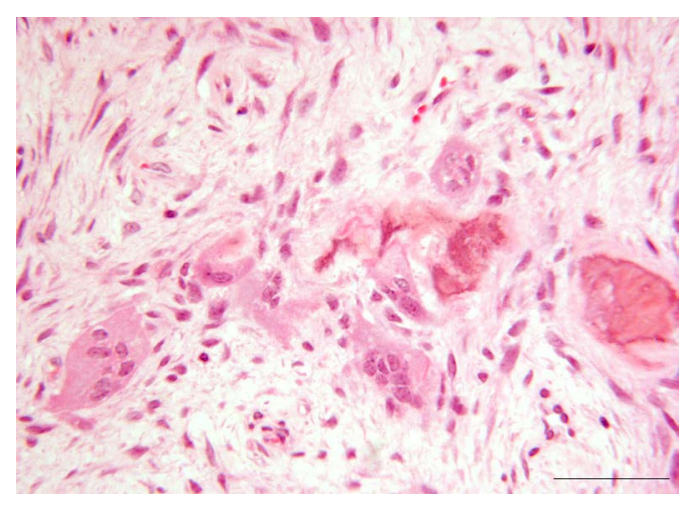

Figure 4. Mineralized bone trabeculae in a spindle cell-rich stroma with occasional osteoclast-like giant cells, $\mathrm{H} \& \mathrm{E}$ stain; bar $50 \mu \mathrm{m}$.

Macroscopically, aneurysmatic bone cysts are dark-red to black in colour, due to multiple blood-filled cysts with tan white gritty septa. Histologically, cavernous blood-filled spaces predominate, separated by septa of loosely arranged spindle cells, multinucleated giant cells and haemosiderin containing macrophages [2] [3] [10]. Solid ABC lack the blood filled cystic spaces and histologically appear like the septa described above [1]. Therefore, the macroscopic and histologic appearance of the presented bone tumour fills the criteria for an aneurysmatic bone cyst.

Histologically, other fibro-osseous lesions and bone tumours described in horses have to be ruled out, including ossifying fibroma, fibrous dysplasia, osteoma, and osteosarcoma [11].

Ossifying fibroma is a benign lesion, characterized by the presence of fibrous connective tissue and trabeculae of immature woven bone [12]. The surface of bone trabeculae of ossifying fibroma show prominent osteoblast rimming [13]. Ossifying fibroma is almost exclusively located at the horse's head, with the exception of one report on ossifying fibroma/osteoma occurring in the proximal tibia [14]. In humans, ossifying fibroma also occurs mainly in bones of the head. Ossifying fibroma and fibrous dysplasia may represent different phases of the same process [11].

Fibrous dysplasia comprises a fibrous and an osseous component. The fibrous component is composed of bland spindle cells, the osseous component of trabecular or woven bone [15]. Osteoblast rimming of trabeculae may only be observed in the periphery near the corticalis [11]. Fibrous dysplasia has rarely been observed in horses, including one case reporting fibrous dysplasia of the accessory carpal bone [16], one of the maxillary sinus [17], and another involving the nasal cavity [13].

Osteoma of humans is defined a benign, slowly growing lesion, consisting of well differentiated mature bone [12]. In osteoma, lamellar bone is formed and the spaces between trabeculae may contain marrow rather than fibrous connective tissue. In domestic animals, osteomas are most often diagnosed in bones of the head [2].

Despite some clear characteristics of the different disease entities, there is a smooth transition between ossifying fibroma, osteoma and fibrous dysplasia and therefore, distinction between the different lesions is not always possible [11].

Osteosarcoma may be ruled out due to the clinical course, non-invasive growth, low mitotic index, lack of pleomorphism and atypia of cells and their nuclei, as well as uniform chromatin of the tumour cells. Osteosarcomas are rare in horses, but have been described, mainly involving bones of the head [2] [17].

Treatment of choice in man is surgical excision but recurrence is possible [18] [19].

\section{Conclusion}

Taking the clinical course, as well as radiographic and histologic features into account, we were able to diagnose a solid aneurysmal bone cyst of the distal metatarsus in this horse. ABC is a rare disease of horses; therefore an age- or sex-predilection is not known. Three cases of $\mathrm{ABC}$ in long bones of horses were diagnosed in two colts and one filly under one year of age [3]-[5] and there is one report on ABC in the radius of a 9-year-old thoroughbred gelding [6]. This is the first case of solid ABC in the metatarsus of an adult gelding and shows that this entity has to be taken into account when proliferative bone lesions of horses are examined. 


\section{Acknowledgements}

We thank Professor Günther Delling, Institute for Pathology, Neuropathology and Molecular Pathology, Hannover for his helpful comments on histologic sections.

\section{References}

[1] Rosenberg, A.E., Nielsen, G.P. and Fletcher, J.A. (2002) Tumours of Undefined Neoplastic Nature. In: Fletcher, C.D.M., Unni, K.K. and Mertens, F., Eds, World Health Organization Classification of Tumours of Soft Tissue and Bone, Vol. 4, IARC Press, Lyon.

[2] Thompson, K. (2007) Bones and Joints. In: Maxie, M.G., Ed, Pathology of Domestic Animals, Vol. 1, Elsevier, Philadelphia, 1-184.

[3] Steiner, J.V. and Rendano Jr., V.T. (1982) Aneurysmal Bone Cyst in the Horse. The Cornell Veterinarian, 72, 57-63.

[4] Momiyama, N., Tagami, M., Tsunoda, N. and Taniyama, H. (1999) Aneurysmal Bone Cyst in a Colt: Histopathological and Immunohistochemical Studies. Equine Veterinary Education, 11, 243-246. http://dx.doi.org/10.1111/j.2042-3292.1999.tb00956.x

[5] Thomas, H.L., Livesey, M.A. and Caswell, J.L. (1997) Multiple Aneurysmal Bone Cysts in a Foal. The Canadian Veterinary Journal, 38, 570-573.

[6] Ordidge, R. (2001) Pathological Fracture of the Radius Secondary to an Aneurysmal Bone Cyst in a Horse. Equine Veterinary Education, 13, 239-242. http://dx.doi.org/10.1111/j.2042-3292.2001.tb00101.x

[7] Lamb, C.R. and Schelling, S.H. (1989) Congenital Aneurysmal Bone Cyst in the Mandible of a Foal. Equine Veterinary Journal, 21, 130-132. http://dx.doi.org/10.1111/j.2042-3306.1989.tb02118.x

[8] Purdy, C.M. (1985) Mandibular Aneurysmal Bone Cyst in a Horse. Equine Practice - Orthopedics, 7, 22-24.

[9] Slayter, M.V., Boosinger, T.R., Pool, R.R., Dämmrich, K., Misdorp, W. and Larsen, S. (1994) Histological Classification of Bone and Joint Tumors of Domestic Animals Armed Forces Institute of Pathology, American Registry of Pathology, and World Health Organization Collaborating Center for Comparative Oncology, Washington DC.

[10] Baxter, G.M. and Turner, A.S. (2002) Diseases of Bone and Related Structures. In: Stashak, T.S., Ed, Adam's Lameness in Horses, Lippincott Williams \& Wilkins, Baltimore.

[11] Freyschmidt, J. and Ostertag, H. (1988) Knochentumoren. Springer Verlag, Berlin, 614-643. http://dx.doi.org/10.1007/978-3-662-08127-3

[12] Schajowicz, F. (1993) Histological Typing of Bone Tumours. Springer, Berlin. http://dx.doi.org/10.1007/978-3-642-84902-2

[13] Livesey, M.A., Keane, D.P. and Sarmiento, J. (1984) Epistaxis in a Standardbred Weanling Caused by Fibrous Dysplasia. Equine Veterinary Journal, 16, 144-146. http://dx.doi.org/10.1111/j.2042-3306.1984.tb01884.x

[14] Collins, J.A. (1998) Ossifying Fibroma/Osteoma in the Proximal Tibia of a Mature Gelding. Veterinary Record, 143, 367-368. http://dx.doi.org/10.1136/vr.143.13.367

[15] Siegal, G., Dal Cin, P. and Araujo, E.S. (2002) Fibrous Dysplasia. In: Fletcher, C.D.M., Unni, K.K. and Mertens, F., Eds., Pathology and Genetics of Tumours of Soft Tissue and Bone, IARC Press, Lyon, 341-342.

[16] Jones, N.Y. and Patterson-Kane, J.C. (2004) Fibrous Dysplasia in the Accessory Carpal Bone of a Horse. Equine Veterinary Journal, 36, 93-95. http://dx.doi.org/10.2746/0425164044864688

[17] Jacobson, S.A. (1971) The Comparative Pathology of the Tumors of Bone. Charles C Thomas, Springfield.

[18] Campanacci, M., Capanna, R. and Picci, P. (1986) Unicameral and Aneurysmal Bone Cysts. Clinical Orthopaedics and Related Research, 204, 25-36. http://dx.doi.org/10.1097/00003086-198603000-00004

[19] Vester, H., Wegener, B., Weiler, C., Baur-Melnyk, A., Jansson, V. and Durr, H.R. (2010) First Report of a Solid Variant of Aneurysmal Bone Cyst in the Os Sacrum. Skeletal Radiology, 39, 73-77. http://dx.doi.org/10.1007/s00256-009-0751-5 